The University of Southern Mississippi

The Aquila Digital Community

Faculty Publications

$10-1-2019$

\title{
The Effect of Group Polarization On Opposition to Donald Trump
}

\author{
Marija A. Bekafigo \\ Northern Arizona University, Marija.Bekafigo@nau.edu \\ Elena V. Stepanova \\ University of Southern Mississippi, elena.stepanova@usm.edu \\ Brian A. Eiler \\ Northern Arizona University \\ Kenji Noguchi \\ University of Southern Mississippi, kenji.noguchi@usm.edu \\ Kathleen L. Ramsey \\ University of Southern Mississippi, kathleen.ramsey@usm.edu
}

Follow this and additional works at: https://aquila.usm.edu/fac_pubs

Part of the Psychology Commons

\section{Recommended Citation}

Bekafigo, M. A., Stepanova, E. V., Eiler, B. A., Noguchi, K., Ramsey, K. L. (2019). The Effect of Group Polarization On Opposition to Donald Trump. Political Psychology, 40(5), 1163-1178.

Available at: https://aquila.usm.edu/fac_pubs/16549

This Article is brought to you for free and open access by The Aquila Digital Community. It has been accepted for inclusion in Faculty Publications by an authorized administrator of The Aquila Digital Community. For more information, please contact Joshua.Cromwell@usm.edu. 


\title{
The Effect of Group Polarization on Opposition to Donald Trump
}

\author{
Marija A. Bekafigo ${ }^{\text {a* }}$ \\ Lecturer, Northern Arizona University \\ Elena V. Stepanova ${ }^{\mathrm{b} *}$ \\ Assistant Professor, The University of Southern Mississippi \\ Brian A. Eiler ${ }^{\mathrm{c} \dagger}$ \\ Post-doctoral Fellow, Northern Arizona University \\ Kenji Noguchi ${ }^{d \dagger}$ \\ Associate Professor, The University of Southern Mississippi-Gulf Coast \\ Kathleen L. Ramsey ${ }^{\mathrm{e}}$ \\ Graduate Student, The University of Southern Mississippi
}

\section{Authors' Note}

We would like to thank Kara Steidl, Jacob Rozwee, Tevin Henley, and Derron Johnson for their assistance with data collection, transcription and coding.

Parts of the data in this article were presented at the 2017 Annual Meeting of the Southern Political Science Association, New Orleans, LA, January 2017.

${ }^{a}$ Department of Politics and International Affairs, Northern Arizona University, Blg. 65, Rm \#212, PO Box 15036, Flagstaff, AZ 86011, USA. Tel: 1-928-523-0923. Email:

\section{Marija.Bekafigo@nau.edu}

${ }^{\mathrm{b}}$ School of Psychology, The University of Southern Mississippi, Owings-McQuagge Hall, 118 College Drive, \#5025, Hattiesburg, MS 39406, USA. Tel: 1-601-266-4342. Email:

\section{Elena.Stepanova@USM.edu}


${ }^{c}$ Department of Psychological Sciences, Northern Arizona University, Blg. 60, Rm \#327, PO Box 15106, Flagstaff, AZ 86011, USA. Tel: 1-928-523-3271. Email: Brian.Eiler@ nau.edu

${ }^{\mathrm{d}}$ School of Psychology, The University of Southern Mississippi-Gulf Coast, 730 E.

Beach Blvd., Long Beach, MS 39560, USA. Tel: 1-228-214-3284. Email:

$\underline{\text { Kenji.Noguchi@usm.edu }}$

${ }^{\mathrm{e}}$ School of Psychology, The University of Southern Mississippi, Owings-McQuagge

Hall, 118 College Drive, \#5025, Hattiesburg, MS 39406, USA. Email:

\section{Kathleen.Ramsey@usm.edu}

*Contributions of the first and second authors are equal, and their names are arranged in alphabetical order. Correspondence concerning this article can be addressed to both authors.

${ }^{\dagger}$ Contributions of the third and fourth authors are equal, and their names are arranged in alphabetical order.

In press, Political Psychology 


\begin{abstract}
Using focus groups, we examined support and opposition for Donald Trump prior to the 2016 presidential election. When in-group members participate in discussion, this conversation alone typically strengthens and intensifies members' initial attitudes (Moscovici \& Zavalloni, 1969). We used a pre- to post- focus group questionnaire to assess attitudes toward Trump, his campaign, and policies. We argue that group polarization influenced people's opinions about Trump such that attitudes became more extreme after discussion with like-minded individuals. We report changes for Trump non-supporters for which group polarization occurred on attitudes toward illegal immigration, political correctness, the military, women, and veterans after the group discussion. For each, level of support for Trump's views decreased. To further explore potential psychological mechanisms associated with group polarization, we employed network science methods to examine the structure of the language associated with these issues and identify potential drivers of attitude change. Results provide some support for a common mechanism for group polarization, which may be driven by language dynamics specific to individual attitudes.
\end{abstract}

Keywords: group polarization effect, focus groups, presidential election, Trump 
The Effect of Group Polarization on Opposition to Donald Trump

There is little doubt that the 2016 U.S. presidential election between Democrat Hillary Clinton and Republican Donald Trump was bizarre. Perhaps most strikingly, while few believed a person without any political experience could become president, Trump was elected. Corruption, incompetence, eye-rolling, and name calling came from both party's nominees in what seemed like more mud-slinging and negative campaigning than ever before. Not only were the major party candidates engulfed in constant and unprecedented campaign warfare, the parties themselves were in disarray. Intraparty disputes over the presumptive nominees and interparty division were at a premium. A quick Google search for "polarization in the 2016 presidential election" revealed more than 2 million hits on the subject including: Polarization Drives Presidential Race to the Bottom; 5 Reasons the 2016 Election Feels So Personal; The Most Polarized Election Ever. Thus, the main goal of the current paper was to assess polarization in attitudes towards Trump and potential mechanisms for this polarization.

Trump's candidacy was by itself polarizing. He made repeated derogatory statements aimed at various groups including Mexicans, Muslims, disabled veterans, and women, to name a few. This included the infamous 2005 Access Hollywood hot microphone tape with his lewd comments about women (Fahrenthold, 2016). He also sent combative tweets about those who opposed him. He called Secretary Clinton "the devil," a "nasty woman," suggested that she should be jailed, and made allusions to her possible assassination. Trump's behavior on the campaign trail also raised questions about his mental health (Caballo, 2017). While Trump's conduct both on and off the campaign trail was admonished by many, others gladly excused or dismissed his conduct and even endorsed his actions citing Trump's view of limiting political correctness. His behavior certainly divided the electorate. 
To be sure, the nation's voters were more polarized than ever (American National Election Studies, 2016; Barber \& McCarty, 2016; McCarty, Poole, \& Rosenthal 2016) and they seemed to become more so as ideological news sources pitted one candidate against the other (Bode et. al., 2018; Mitchell, Gottfried, Kiley, \& Matsa, 2014; Prior, 2007). Supporters at Trump's rallies chanted "Lock her up!" in response to Clinton's use of a personal email server for government business when she was Secretary of State. At the same time, there were numerous protesters at Trump's rallies whom Trump infamously asked his supporters to physically remove and even assault. While citizens and pundits alike have denounced polarized politics, political scientists still know little about its causes and consequences (Barber \& McCarty, 2016). It was in this political climate that we examined what would happen if presumptive voters from one end of the political spectrum got together to talk about their attitudes toward specific issues. Would they, too, become more polarized? Or would deliberation attenuate polarization's effects as some proponents of deliberative democratic theory suggest (Chambers, 2003; Delli Carpini, Cook \& Jacobs, 2004)?

\section{Theoretical Basis}

There is little doubt that the U.S. Congress is polarized (Lee, 2009; Poole \& Rosenthal, 2007; Sinclair, 2014; Theriault, 2008). However, research is mixed on whether voters, too, are polarized ideologically on policy preferences (e.g., Abramowitz, 2010; Abramowitz \& Saunders, 1998; Hetherington, 2001) or if they have simply sorted themselves into the two parties while maintaining moderate policy positions (Fiorina, Abrams, \& Pope 2005; Levendusky, 2009). Polarization largely occurs along party lines because party is a perceptual screen through which voters view politics (Green, Palmquist \& Schickler, 2002). Party activates both positive affect for one's own party and negative affect for those on the other side (Iyengar, Sood, and Lelkes, 2012). Contempt for opposing partisans might be further exacerbated during elections because of 
a hyperpolarized mass media coupled with heterogenous social media networks reinforcing one's beliefs (Bekafigo \& McBride, 2013; Sunstein, 2018).

Social psychological literature suggests that when in-group members (i.e., those belonging to the same group) participate in discussion, simply engaging in this conversation strengthens and intensifies members' initial attitudes (Druckman, Levendusky \& McLain, 2018; Moscovici \& Zavalloni, 1969). Given the context of Trump's campaign, we speculated that group polarization could explain why so many of his supporters and opponents have gone to such lengths to either spread or subvert his views. Informational influence explains group polarization, such that individuals become more indoctrinated when they hear arguments that support their position in other people's words (Kaplan \& Miller, 1987). In fact, simple repetition of the arguments that represent the dominant viewpoint increases group polarization (Brauer, Judd, \& Gliner, 1995). Biased assimilation of information is another underlying mechanism for group polarization. When exposed to both sides of the argument, individuals tend to see evidence supporting their initial attitude as more convincing (Lord, Ross, \& Lepper, 1979). Additionally, group polarization can be explained by social identity theory (Tajfel, 1978) in conjunction with social categorization theory (Turner 1985, 1991). Specifically, Suhay (2014) argued that because group conformity generates approval and deviance generates disapproval, adherence to in-group political norms is essential for maintaining social status and avoiding shame. Whether the supporting or opposing groups possess more extreme members, there should be no differences in terms of polarization (Van Swol, 2009). In sum, both persuasive arguments and social comparisons have been proposed as mechanisms for group polarization (for review, see Isenberg, 1986).

These mechanisms for group polarization are perhaps more likely given the increased affordances for social interaction and discourse (Chemero, 2003). Focus groups are one such 
opportunity. Another is exposure to social media (Bekafigo \& McBride, 2013) and political campaigns (Iyengar, Sood, and Lelkes, 2012) which strengthen political and ideological polarization as like-minded individuals group together and deliberate (Sunstein, 2002). Consequently, one goal of this study was to understand polarization surrounding Trump's viewpoints with potential voters in an experimental lab setting. As such, we use focus groups to study polarization allowing us to respond to an appeal by political science to look beyond mass surveys and predictive models to understand public opinion and elections by talking to voters (Blakely, 2016; Gelman \& Azari 2017; Masket, 2016). Additionally, we probe this effect using modern, novel analytics (i.e., machine learning and network science) to provide some insight into the underlying processes driving group polarization with the knowledge that mixed methods enhance our findings.

\section{The Current Study}

In order to test for group polarization, we assembled focus groups of Trump supporters and non-supporters during the 2016 presidential election campaign. We examined participants' attitudes toward Trump and his policies before and after engaging in a discussion with likeminded individuals. We also gathered focus group language data to further understand the reasons for opposition and support. While others have argued that "a simple descriptive narrative is quite appropriate and often all that is necessary" (Stewart, Shamdasani, \& Rook, 2007, p. 109) for analyzing focus group data, we go further by employing content analysis to identify recurring themes. Additionally, we employ natural language processing, a novel machine learning technique that explores sentiment in language data (e.g., Crossley, Kyle, \& McNamara, 2017), to identify psychological processes that may influence polarization. Further, we use network science (i.e, graph theory, Euler, 1995) to robustly identify the underlying language structure in issues that produce polarization and language processes that drive these effects (Freeman, 1978). 
As such, this research is important for two reasons: (1) we test for group polarization and (2) we seek to understand the underlying processes that produce polarization. While some may argue that political science does not use focus groups or focus group tests are not generalizable, we fill this gap by employing vigorous methodology that implicates generalized processes underlying polarization. Moreover, the focus group data used in this study are especially important given the discipline's self-critique of failing to understand, much less predict, the (Electoral College) outcome of the 2016 election (Blakely, 2016; Gelman \& Azari 2017; Masket, 2016). Others, too, have implored political scientists to go beyond polling data and listen to the public (Hibbing \& Theiss-Morse, 1995; Kendhammer, 2016; Walsh, 2012).

We expected to produce findings consistent with a group polarization effect. Specifically, we hypothesized that participants' initial opposition to Trump would increase from the pre- to post-test. We did not have specific predictions on what individual issues would produce more polarization, because there is little, if any, consensus in the literature (see conclusion for recommendations for correcting this gap). We also expected language to reflect group polarization. In other words, we expected the language networks to be correlated for those issues that produced polarization, implicating a common process. We conducted exploratory analyses on these networks to determine the types of processes (i.e., language indicators) that were most influential in driving polarization for each issue individually and potential overlap.

\section{Method}

\section{Participants}

We carried out two Trump supporter focus groups $(N=6)$ and eight Trump non-supporter focus groups $(N=37)$ for a total of 43 participants. The total number of focus groups for Trump non-supporters were consistent with previous recommendations (i.e., it is recommended to conduct three to four focus groups for each category of participant, Krueger \& Casey, 2015), 
while our 2 groups of supporters fell short of this recommendation. Thus, we only report data for the Trump non-supporters $\left(M_{\mathrm{age}}=21.27, S D_{\mathrm{age}}=5.30,73 \%\right.$ male $)$ in the current paper. The racial/ethnic composition of the Trump non-supporters was the following: 19 African Americans, 12 Whites, 1 Hispanic/Latino, 1 Asian, and 4 multicultural individuals. The political affiliation was the following: $70.3 \%$ Democrats, $13.5 \%$ Independents, $8.1 \%$ Republicans, and $8.1 \%$ Other. See Table 1 for additional demographic characteristics of the sample.

While our participants were all college students (convenience sample), this demographic will be the largest voting bloc in future elections (e.g., Greenblatt, 2015). All participants were recruited from Hattiesburg, Mississippi, during the 2016 presidential election primary season (August-November). We recruited participants through multiple outlets. First, we posted the study on SONA, a cloud-based research participation recruitment software that can be accessed by participants and researchers at the University of Southern Mississippi, Department of Psychology, via web-browser. In addition, the study was advertised on the University of Southern Mississippi list-serv, Craigslist, Impact (a local online newspaper), and flyers placed around campus, Hattiesburg Clinic and the city of Hattiesburg. We also reached out to several faculty members at neighboring colleges (William Carey University and Pearl River Community College) who advertised the study to students in their classes.

\section{Procedure and Materials}

Focus group selection, procedure, and attitudinal survey. Even though we led an aggressive recruitment campaign, we had a very low response rate among Trump's supporters and ultimately decided to leave them out of our analysis. Perhaps, the issue of "silent Trump voters" contributed to our final recruitment outcome (Nomani, 2016). Focus groups were held several times a week in the evenings beginning in August and extending to the week before the elections. Focus groups were independent and comprised of 3-5 individuals. Groups were 
determined based on participant self-identification of support for (or against) Trump, regardless of party affiliation which resulted in groups of like-minded individuals. To be sure, ideology and party ID were significantly different between Trump supporters and non-supporters. Trump's supporters were more conservative/less liberal $(M=5.50, S D=1.38)$ than Trump's nonsupporters $(M=2.93, S D=1.60)$ on a scale from 1 (Very Liberal) to 7 (Very Conservative $), t(41)$ $=3.63, p=.001$. For party ID, Trump's supporters were more Republican/less Democratic leaning $(M=5.83, S D=.98)$ than Trump's non-supporters $(M=2.33 ; S D=1.66)$ on a scale of 1 (Strong Democrat) to 7 (Strong Republican), $t(40)=5.00, p<.001$.

Participants in each focus group were shown several videos ${ }^{1}$ (taken from official Trump campaign website and YouTube) and completed a demographic questionnaire. Following the videos, participants completed a self-report questionnaire in which they indicated their level of support for Trump's views on specific issues (the trade war, illegal immigration, the $2^{\text {nd }}$ Amendment, political correctness, education, the military, the economy, abortion, torture, women, Veterans, Veterans - prisoners of war, disabled individuals, and protesters at his political rallies). Participants used a scale from 1 (Extremely opposed to) to 9 (Extremely in favor of) with a midpoint anchor (Neutral). Themes on the attitudinal survey corresponded to a portion of the video in which Donald Trump spoke about each topic. Videos featuring Trump addressing each issue assessed in the attitudinal questionnaire were shown to participants to remind them about Trump's stance on those issues, in case some were not following the campaign and/or familiar with specific issues. Participants engaged in a moderated 2-hour discussion, both answering scripted questions and interacting with one another. ${ }^{2}$ The discussion

\footnotetext{
${ }^{1}$ Please access all the videos shown to participants here: https://www.dropbox.com/sh/p7oeeq424st3uum/AACId6dinBXhsKtptJ_x2Jpna?dl=0

${ }^{2}$ Please see a discussion guide for Focus Groups (Trump Non-Supporters) here: https://www.dropbox.com/s/wm4mmm25yto6qs0/Discussion\%20Guide\%20for\%20Focus\%20Group \%20\%28Trum p\%20Non-Supporters \%29.docx?dl=0
} 
followed a specific focus group guide that facilitated conversation on each of the points raised in the attitudinal questionnaire. For the most part, we were interested in why participants supported or opposed Trump. At the conclusion of the discussion, participants completed the same attitudinal questionnaire again to assess potential attitude change (i.e., polarization effects). Participants were debriefed and received either SONA research participation credits or a $\$ 15$ Walmart gift card.

Language data acquisition and analyses. Language data were collected across focus group sessions (audio and video recording) and were transcribed by a researcher. This procedure facilitated coding for similar themes across groups (Stewart, Shamdasani, \& Rook, 2007). We analyzed the language participants used during the focus group discussion looking for additional evidence of polarization. To identify the underlying structure in language, we used natural language processing which relies on a machine learning algorithm to explore textual features of language (i.e., psychological motivation, sentiment; The Sentiment Analysis and Social Cognition Engine [SEANCE], Crossley, Kyle, \& McNamara, 2017). This tool allows researchers to identify underlying psychosocial processes instantiated represented in language and has been demonstrated to be more robust than many other language analysis techniques (i.e., frequencybased techniques such as the linguistic inquiry and word count [LIWC], Pennebaker, Boyd, Jordan, \& Blackburn, 2015). While a full explanation of this technique is beyond the scope of the current paper, in general, SEANCE is given a corpus of text and compares this text with previously validated linguistic dictionaries by vectorizing language and looking for cooccurrence. In other words, a researcher identifies those indicators of interest a priori and SEANCE produces a normalized score for each indicator in which larger scores reflect a greater presence of the language indicator. We discuss the specifics of the language analysis in the results and present the findings both qualitatively and quantitatively. 


\section{Results}

\section{Pre- to Post-Focus Group Polarization}

To test for group polarization, we conducted a series of paired sample $t$ - tests on participants' attitudinal questionnaire ratings (there were no assumptive violations for $t$-tests-homogeneity of variance, normal distribution, etc). Given the small sample size for Trump supporters $(n=6)$ we only report results for Trump non-supporters. For each significance test comparing pre and post scores, we also computed associated effect sizes expressed in standard deviation units (Cohen's $d$, see Cohen, 1988) for repeated-measures designs using a correction for dependence between means (Morris \& DeShon 2002). For those who opposed Trump, group polarization occurred for the following items: level of support for Trump's views on (a) illegal immigration, $t(36)=2.20, p=.04$; (b) political correctness, $t(36)=2.03, p=.05$; (c) the military, $t(36)=2.11, p=.04 ;(\mathrm{d})$ women, $t(36)=2.61, p=.01 ;$ and $(\mathrm{e})$ veterans, $t(36)=3.27, p$ $=.002$. Across these issues, Trump non-supporters increased their level of opposition to Trump's views, demonstrating group polarization, in support of our primary hypothesis(see Table 2 for all means and associated effect sizes). While some may argue that these tests are not stringent enough (i.e., a recommendation for a $p$-value correction), we were unconcerned with the overall null hypothesis (i.e., that all issues will not show polarization) and instead are more concerned with change at the individual issue level. As such, we have kept the significance value at $p<.05$ in line with recommendations by Perneger (1998).

\section{The Language of Polarization}

To further clarify the nature of group polarization, we employed several analyses on the language participants used during the focus-group discussion. Primarily we took two approaches, one qualitative and one quantitative. First, we identified recurrent themes in the conversations (Krueger \& Casey, 2015; Stewart, Shamdasani, \& Rook, 2007) and present qualitative results 
and interpretation for these themes. Second, we employed natural language processing, a machine learning technique used to quantitatively identify sentiment in language (Crossley, Kyle, \& McNamara, 2017), and used results from these analyses to construct networks (e.g., Eiler, Al-Kire, Doyle, \& Wayment, in press; Siew, McCartney, \& Vitevitch, 2019) to identify underlying psychological processes leading to group polarization using quadratic assignment procedures (see Robins, Lewis, \& Wang, 2012 for review).

\section{Qualitative Results}

Two coders identified themes present in responses to each of the questions from the written transcripts by collapsing similar answers into themes. ${ }^{3}$ Below we discuss the five topics that indicated group polarization for those who opposed Trump and where possible, provide examples of specific themes by quoting responses. ${ }^{4}$

Since group polarization occurred along particular views, we focused on the qualitative summaries for these topics. One of the benefits of focus group research is that we can understand polarization through participants' narratives. This is especially important given recent criticisms political scientists have received for focusing on polling, large $n$ data sets (i.e., overpowered samples), and election forecast models to the detriment of a deeper, or at least different, insight into voter behavior (Lohr \& Singer, 2016; Masket, 2016). With that in mind, we also demonstrate how our results may reflect the broader trends exhibited in polling data.

\footnotetext{
3 The list of themes is accessible here: https://www.dropbox.com/s/w09duxgm9vzuo51/ListofthemesPoliticalDiscussionStudy.docx?dl=0

${ }^{4}$ Note that for illegal immigration, political correctness, and military, we asked participants what they personally thought about each issue and what they thought about Trump's ideas on the same. For women and veterans, however, we only asked how participants felt about Trump's stance on them (see Discussion Guide online, Footnote 2), mainly because we presumed that participants would not express personal negative attitudes toward these groups in public.
} 
Immigration and the Mexican/Hispanic population. Group polarization occurred among those who opposed Trump's candidacy when asked about "illegal immigration and the Mexican/Hispanic population.” This issue epitomized group polarization in our study. First, participants immediately brought up Trump's promise to build a wall along the Mexican border, both when we asked about reasons why they oppose Trump, and about Trump's specific policies they opposed.

...you know illegal immigration's a problem and we have to come up with some solution. Now, spending billions of dollars on building a wall...it's not fiscally responsible.

...I'd hate for like all my tax dollars to be, you know, contributed to a wall...

...His idea of the wall, in my opinion, it just reminds me of the Berlin wall.

The wall was on the top of our participants' minds (Zaller, 1992) and their attitudes were unequivocally negative, in line with other examples of polarization. Here, one's initial attitude coupled with extreme positions (certainty that the wall is not a good idea derived from the responses from other participants — biased assimilation) was a likely source of polarization (Boysen \& Vogel, 2007). Even among those who opposed illegal immigration, a wall did not seem to be the answer. While many participants had mixed or ambivalent views on the broader issue of immigration, the wall (the primary focus of discussion), was a familiar, but simple, concept around which a steadfast opinion was easily formed (Carmines \& Stimson, 1980). This was further bolstered by participants' individual opinions in which they brought up the promise of the wall independent of a direct connection to Trump. Our participants' views were in line with national polls at the time on this issue with most Americans opposing construction of a border wall (Pew Research Center, 2016).

The military. While issues surrounding the military are complex, the prompt we used was sufficiently vague that discussion centered on more accessible concepts such as size and spending. Participants argued that the military was already large enough and anything bigger 
would lead to "World War III." For similar reasons, they agreed that greater spending was unnecessary. That is, participants' views on the military focused on preemption rather than retaliation associated with generalized national defense.

I say, with the military, it's already strong, because if you look through American history, we're kind of like those people who aren't supposed to be messed with... We are the number one spender on military budget, per year, in the entire world...

Participants were also able to discern between military spending for conflict engagement compared to veteran support monies.

We have a ton of...military planes and jets and whatnot that aren't necessary ... a lot of that money actually, should be rearranged so it like takes care of soldiers and veterans instead of weapons...

Political correctness. "What is political correctness?" one participant queried. Although there were various ways of defining this concept, those who opposed Trump were quick to bring up his lack of it. For example, one participant stated: “He [Trump] said "I'm not politically correct and i'ma say what I wanna say anyway and y'all are gonna listen." Some participants also opposed Trump's disdain for political correctness as justification for his statements.

He's an embarrassment like for him to do stuff like that. Like to mock reporters and to talk the way he does about women. Like publicly, that's, that's horrible. That's disgusting.

Interestingly, this prompt seemed to elicit a deeper discussion than other polarizing topics. Participants linked political correctness to free speech and democracy, but also recognized the negative sides of political correctness that influenced Trump's win (Greenberg, 2016). Participants discussed the potential consequences of offensive statements on the world stage, despite one suggestion that Trump's position reflected American sentiment. Nevertheless, a common thread was that people should choose their words carefully so as to not offend others, without policing. This is reflective of a recent poll in which most Americans are supportive of 
free speech even if that speech is offensive (American Enterprise Institute Political Report, 2017).

Women. We also asked participants how they felt about Trump's statements on women given the constant media attention on this topic. Several participants even noted that the media was biased against Trump on this issue, citing that his opponent (i.e., a woman) contributed to a sustained narrative on this issue. Thus, participants were likely well aware of Trump's statements aimed at women prior to the focus groups. Perhaps one reason why polarization occurred on this issue was because non-supporters could easily attack him, contributing to a shared extreme viewpoint (i.e., assimilation), as may have occurred on other issues (i.e., immigration and the wall). No ambivalent opinions were noted.

Oh, he's awful...Umm, being a personal feminist, that is just rude to bring up- to just chastise a woman and assume that she's on her cycle, like what?...He really just talks about, "Man power, man power." He just doesn't put it in a woman's perspective, how we feel, like what's going on. He just makes us feel like second class...

Veterans. Trump's statements about veterans also exhibited group polarization. Participants were in agreement that the Trump's statement about John McCain (shown in the videos prior to group discussion) was unacceptable and became a talking-point.

...when you're saying that John McCain is a loser because he was captured, I'm like oh my god... that's literally, that's so horrible.

While participants stated that veterans should be cared for, the rest of the discussion was varied and indicated a quite superficial understanding of veteran's issues or Trump's stance on them. However, the group's focus on Trump's statements about John McCain may have produced the extremity needed for polarization via assimilation, similar to the aforementioned issues.

Summary. Group polarization occurred for five issues related to the 2016 presidential election campaign, though we have no evidence suggesting these issues were distinctive from the 
non-polarized issues. Participants' views became more extreme after engaging in a discussion with like-minded individuals. That others in the group shared their opinion exemplifies prior research on group polarization via informational influence (e.g., when one encounters additional novel arguments that support their original view) and assimilation (when one's individual attitudes get assimilated to the group's congruent, but even more extreme position). Qualitative analyses uncovered themes that presented opportunities for assimilation, and provided insight into potential affordances for polarization that included the campaign videos and the focus group setting itself.

\section{Quantitative Results}

Language structure and influence. To further address mechanisms of polarization, we examined psychosocial processes that drove the discussion, indicated by participants' conversations. To do so, we employed several quantitative techniques (i.e., machine learning and network analysis) aimed at describing the language structure and determining the most important drivers of language for issues producing group polarization effects. We also tested whether group discussions were similar across polarized issues.

We identified 47 theoretically driven language indicators related to political science that might influence the discussion of political issues from the presidential election campaign (see Supplemental Online Appendix ${ }^{5}$ ). To do so, we had four coders select potential influential variables from the full SEANCE indicator list of 256 and only included those for which there was unanimous agreement. For example, we included indicators of power because politics and

\footnotetext{
${ }^{5}$ The Supplemental Online Appendix is available at https://www.dropbox.com/s/oqrltq0kv2o2qx0/Supplemental\%20Online\%20Appendix.docx?dl=0
} 
power have well-known associations (Lasswell, 1950). In other words, we thought our participants conversations might include language associated with "power."6

To describe the language structure for each of the polarized issues we aggregated all participant language into a single corpus of text for each issue (i.e., immigration, military, political correctness, women, and veterans), then separated comments into approximately equal word count files (to compute correlations between indicators). These files were analyzed by SEANCE and a normalized score for each of the 47 variables of interest was calculated. Next, we computed pairwise, bivariate correlations (using 1000 bootstrapped samples) between all 47 variables and retained those which were significant at the $p<.01$ level. We took the absolute value of these correlations as network analyses are not amenable to negative correlations (c.f. Eiler et al., in press). Next, these correlations were input into an adjacency matrix to form networks that quantitatively described the language structure for each discussion of the polarized issues.

In network science terms, nodes (here, an individual language variable) are connected by edges (here, the correlation between the two nodes) to form a network that describes the overall, multiply causal, relationships (i.e., topology) that underlie a given system (here, the language participants used to discuss polarized issues). As a brief illustrative aside, imagine a network of people (nodes) who are connected by friendships (ties). Here, the network structure would describe structure of the social network to understand the overall social system. In our study, we also computed flow betweenness (a network measure of influence; Freeman, 1978) for each node

\footnotetext{
${ }^{6}$ Variables were derived from several different databases including: The affective norms for English Words (Bradley \& Lang, 1999), The Geneva affect label coder (Scherer, 2005), General inquirer (Stone et al., 1966), Lasswell (Lasswell \& Namenwirth, 1969), Hu-Lui polarity (Hu \& Liu, 2004), and EmoLex (Mohammad \& Turney, 2010; 2013). Development, validation techniques, and word lists can be accessed via primary sources for each database.
} 
to determine which variables were most influential. In our social system, this same measure might quantify the amount of social capital each individual had in the social network. Here, the correlations between psychological processes (derived from the language participants used) formed a quantitative description of the discussions participants had for each issue, with an influence metric calculated for each language indicator. We tested these ordered lists (i.e., from high to low influence) against one another to determine whether the same language variables were associated with polarization (i.e., $\rho$, Spearman's rho) across issues. Results were nonsignificant (all $p \mathrm{~s}>.05)$, indicating that for each issue there were unique psychological processes driving the discussion. The 5 most influential psychological processes for each issue are summarized in Table 3.

While these most influential processes do not indicate a common mechanism for polarization, they do demonstrate constraints on participants' language as a function of issue type and provide insight into potential drivers of informational influence. In other words, these processes represent an "educated guess" at information around which participants assimilated their attitudes, potentially leading to more extreme views. In support of this conjecture, the language used to discuss each of the issues was different. This is what we might expect given the breadth of the issues that exhibited polarization. Nevertheless, there are some similarities. Specifically, we found that multiple indicators aligned with power and authoritarianism (e.g., submit, power total, dominance, power authoritative participants and power ordinary participants, see Table 3) were some of the most influential processes that drove discussions in our focus groups. While language related to power is not surprising given the topic of conversation, power authoritative participants, which can be interpreted as language used to describe how power flows through followers, appeared twice in the top 5. This is notable since authoritarian views were a key predictor of support for Trump (MacWilliams, 2016). 
Interestingly, we found evidence that Trump's opposition disfavored those same predispositions through their language. Moreover, one explanation for polarized politics is the increasing tendency toward authoritarianism (Stenner and Haidt, 2018). Here, we argue that this tendency may have played a role in producing polarization among our focus groups.

Language and polarization. Beyond describing the language structure and testing for underlying psychosocial processes associated with polarization for each issue, we also tested whether a general group polarization process would exist independent of issue. To test this hypothesis, we employed a network science technique (i.e., quadratic assignment procedure; QAP) to test for system-level associations between all language networks. This technique examines the structural relationship between two networks by holding one network constant and randomly permuting ties in the other. Next, a correlation between the randomly permuted network and the constant network is calculated. This process is repeated iteratively (i.e., 10,000 samples) to create a probability density function (i.e., a sampling distribution). Finally, the correlation between the two observed networks calculated and located within this computed distribution to determine statistical significance (see Robins, Lewis, \& Wang, 2012 for a more complete description). For each of the polarized issues (i.e., immigration, military, political correctness, women, and veterans) we followed this procedure to compute correlations and significance values amongst the language networks. We hypothesized that if similar dynamics (i.e., mechanism) gave rise to group polarization there would be positive and significant associations amongst the networks. We found partial support for this hypothesis (see Table 4 below).

Summary. The quantitative language analyses provide initial evidence that group polarization may be driven by a common mechanism. The positive associations between the networks across polarized issues (i.e., QAP models) indicate these systems may arise from 
similar underlying governing principles (i.e., causal dynamics), that is, the same processes govern language for all the networks. This is consistent with an assimilation and informational influence account of group polarization. Additional support for this mechanism comes from the network influence metrics. Here, we found that different issues were anchored by different psychological processes (i.e., language indicators). Taken together, in discussions of topics that produced group polarization, participants fixated on language particular to individual issues (because they need different types of language to assimilate to - there is different information to tie a topic together), but structured their conversation in similar ways.

\section{Discussion}

Political deliberation has been hailed as a necessary part of the democratic process as it can lead to engaged citizenry, better policy, and subsequently, more citizen satisfaction (see Delli Carpini, Cook \& Jacobs, 2004 for review). Yet, this deliberation can have unintended effects including attitude polarization (Price et. al., 2003). The current study attempted to address this potential paradox by experimentally manipulating deliberation in the time leading up to one of the most polarizing presidential elections in US history. We allowed like-minded individuals to discuss their attitudes toward Donald Trump and measured their attitude extremity pre- and postdiscussion. We hypothesized that this deliberation would strengthen their attitudes. We observed this group polarization effect among those who opposed Trump on specific issues. We suggest that attitudinal assimilation and informational influence were the primary drivers and provide evidence that these were common underlying mechanisms by which group polarization occurred, consistent with previous literature (Brauer, Judd, \& Gliner, 1995; Druckman, Levendusky \& McLain, 2018; Kaplan \& Miller, 1987; Moscovici \& Zavalloni, 1969; Suhay, 2014).

Although group polarization occurred for several issues, there were others for which no effect was found. Some research has suggested that specific issues are more likely to cause group 
polarization, however there is currently no consensus (see Wojcieszak \& Price, 2010 for a summary of this literature). On one hand, it could be the case that only certain issues follow this type of process. Alternatively, a common process may exist, but the effect size differs as a function of some third variable. Scholars of political polarization in the electorate might focus on identifying those issues which produce strong polarization effects to disentangle this issue of polarization versus sorting.

Finally, linking the qualitative findings and the quantitative findings, we speculate that attitudinal assimilation and informational influence are processes underlying group polarization at the topological (i.e., network) level. In nearly all focus groups there is evidence of assimilation. Additionally, there is evidence that group polarization has at least some common underlying process. That being said, the relationships between immigration are the only ones that include non-significant associations and are also the smallest (Table 4). Given that this issue was found to be the most polarizing, it could also be the case that at some threshold the more generalized polarization process (i.e., extremity/assimilation) becomes less influential and other (as yet unknown) issues become more salient. This speculation would be in line with more general principles of interaction dominant systems (of which networks are a canonical example) in which processes that operate along different time scales exert differential influence (see Eiler, Kallen, \& Richardson, 2017 for review).

While the primary research question of group polarization guided our study, these data are also are ripe to answer other lingering questions about voter behavior in this election. For example, we could test theories about Trump's eventual win related to populism (Inglehart \& Norris, 2016), sexism (Clinton, 2017), or authoritarianism (MacWilliams, 2016), that others have argued were pervasive in the election. We might also explore how our results compare with exit polls to try and tie to broader voting trends. For example, our focus groups exhibited group 
polarization for the topic of illegal immigration. Polarization on this issue was also found among the populace. $61 \%$ of Clinton voters thought illegal immigrants working in the U.S. should be offered legal status, while $83 \%$ of Trump voters thought they should be deported (CNN exit polls). When asked about the wall, voters were even more polarized with $76 \%$ of Clinton voters opposing it and $85 \%$ of Trump voters supporting it. According to exit polls, voters were also polarized on Trump's treatment of women (65\% of Clinton voters were bothered and $87 \%$ of Trump voters were not bothered). Unfortunately, the exit polls did not ask about abortion, political correctness, or veterans at all or in a manner that we could connect them with the results of our focus groups.

This work in not without limitations. All participants were enrolled in college at the time of the study, were between ages of 18 and 30, eligible to vote and indicated their intent to vote in the 2016 Presidential Elections. However, we do not know whether they registered to vote or ultimately cast votes on Election Day. Regardless, this should not affect our study as we are concerned with deliberation about politics which is separate from voting (Chambers, 2003). While students are acceptable participants for a study of this nature (Druckman \& Kam, 2011), their partisan attachments are not as stable as a sample of older citizens (Green, Palmquist \& Schickler, 2002), nor are they likely to be as politically engaged (Abramowitz, 2010). Therefore, we might expect them to be less polarized than the average citizen. The fact that group polarization effect was displayed on several of the issues is even more impressive given the demographics of our participants.

\section{Conclusion}

In general, our results show a group polarization effect, but these effects were only present for particular issues in those who did not support Trump, such as level of support for Trump's views on illegal immigration, political correctness, military, women and veterans. 
Additionally, we find some support for a generalized mechanism for group polarization, as evidenced by the language analyses. While language used to discuss each of the issues was different — with a notable overlap in power and authoritarianism — the same process governs language for all the issue-specific language networks. Both qualitative and quantitative language analyses suggest assimilation and informational influence were the primary drivers of the group polarization. We suggest that future studies should focus on determining which issues polarize rather than making blanket statements about a polarized citizenry (Fiorina, Abrams \& Pope, 2005). We also suggest that the specific mechanisms by which group polarization may occur are tested in more stringent settings that employ more rigorous experimental control. One way for scholars to determine whether voters are polarized or sorted is to examine individual issues and then group them together to determine which issues are the most polarizing. 


\section{References}

Abramowitz, A. I. (2010). The disappearing center: Engaged citizens, polarization, and American democracy. New Haven: Yale University Press.

Abramowitz, A. I., \& Saunders, K. L. (1998). Ideological Realignment in the U.S. Electorate. Journal of Politics, 60(3), 634-652.

American Enterprise Institute Political Report. (2017). Polls on political correctness, 13(6), 1-4. Retrieved from American Enterprise Institute website: http://www.aei.org/publication/aei-political-report-polls-on-political-correctness/

American National Elections Studies (2016). ANES 2016 Pilot Study. Retrieved from: http://www.electionstudies.org/studypages/anes_pilot_2016/anes_pilot_2016.htm

Barber, M., \& McCarty, N. (2016). Causes and Consequences of Polarization. In J. Mansbridge \& C. J. Martin (Eds.), Political Negotiation: A Handbook (pp. 37-90). Washington D.C.: Brookings Institution Press.

Bekafigo, M. A., \& McBride, A. (2013). Who Tweets about Politics? Political participation of Twitter users during the 2011 gubernatorial elections. Social Science Computer Review, $31(5), 625-643$.

Blakely, J. (2016). Is Political Science This Year's Election Casualty? Retrieved from The Atlantic website: https://www.theatlantic.com/education/archive/2016/11/is-politicalscience-another-election-casualty/507515/?utm_source=twb

Bode, L., Budak, C., Ladd, J. M., Newport, F., Pasek, J., Singh, L. O., Soroka, S.N., \& Traugott, M. W. (2018). Words that Matter: How the News and Social Media Shaped the 2016 Presidential Campaign: Brookings Institution Press. 
Boysen, G. A., \& Vogel, D. L. (2007). Biased assimilation and attitude polarization in response to learning about biological explanations of homosexuality. Sex Roles, 57, $755-762$.

Bradley, M.M. \& Lang, P.J. (1999). Affective norms for English words (ANEW): Stimuli, instruction manual and affective ratings (Technical Report No. C-1). Gainesville: University of Florida, NIMH Center for Research in Psychophysiology.

Brauer, M., Judd, C. M., \& Gliner, M. D. (1995). The effects of repeated expressions on attitude polarization during group discussions. Journal of Personality and Social Psychology, 68(6), 1014-1029.

Caballo, V. E. (2017). Un análisis psicológico de Donald Trump. = A psychological analysis of Donald Trump. Behavioral Psychology / Psicología Conductual: Revista Internacional Clínica Y De La Salud, 25(1), 227-249.

Carmines, E., \& Stimson, J. (1980). The Two Faces of Issue Voting. American Political Science Review, 74(1), 78-91.

Chambers, S. (2003). Deliberative democratic theory. Annual Review of Political Science, 6, 307-326.

Chemero, A. (2003). An outline of a theory of affordances. Ecological psychology, 15(2), 181195.

Clinton, H. R. (2017). What happened. New York: Simon \& Schuster.

CNN (2016). Exit polls. National President. Retrieved from http://www.cnn.com/election/results/exit-polls

Cohen, J. (1988). Statistical power analysis for the behavioral sciences (2nd ed.). Hillsdale, NJ: Lawrence Earlbaum Associates. 
Cramer, K. J. (2016). The Politics of Resentment. Chicago: University of Chicago Press.

Crossley, S.A., Kyle, K., \& McNamara, D.S. (2017). Sentiment analysis and social cognition engine (SEANCE): An automatic tool for sentiment, social cognition, and social-order analysis. Behavior Research Methods, 49(3), 803-821. doi:10.3758/s13428-016-0743-z

Delli Carpini, M. X., Cook, F. L., \& Jacobs, L. R. (2004). Public deliberations, discursive participation and citizen engagement: A review of the empirical literature. Annual Review of Political Science, 7 (1), 315-344.

Druckman, J. N., \& Kam, C. D. (Eds.). (2011). Students as experimental participants: A defense of the "Narrow Data Base." New York: Cambridge University Press.

Druckman, J. N., Levendusky, M. S., \& McLain, A. (2018). No Need to Watch: How the Effects of Partisan Media Can Spread via Interpersonal Discussions. American Journal of Political Science, 62(1), 99-112.

Eiler, B.A., Al-Kire, R.L., Doyle, P.C., \& Wayment, H.A. (in press). Power and trust dynamics of sexual violence: A textual analysis of Nassar victim impact statements and \#MeToo disclosures on Twitter. Journal of Clinical Sports Psychology.

Eiler, B.A., Kallen, R.W., \& Richardson, M.J. (2017). Interaction dominant dynamics, timescale enslavement and the emergence of social behavior. In R. Vallacher, A. Nowak, \& S. Read (Eds.), Frontiers in Social Psychology: Computational Models in Social Psychology.

Euler, L. (1995). From the problem of the seven bridges of Königsberg. In Classics of Mathematics, R. Calinger (Ed). Englewood Cliffs, NJ: Prentice Hall

Fahrenthold, D. A. (2016, October 8). Trump recorded having extremely lewd conversation about women in 2005. The Washington Post. Retrieved from: https://www.washingtonpost.com/politics/trump-recorded-having-extremely-lewd- 


\section{conversation-about-women-in-2005/2016/10/07/3b9ce776-8cb4-11e6-bf8a-}

\section{3d26847eeed4_story.html?utm_term=.9b8c3acfef7a}

Festinger, L., \& Carlsmith, J. M. (1959). Cognitive consequences of forced compliance. Journal of Abnormal and Social Psychology, 58, 203-210.

Fiorina, M., Abrams, S. J., \& Pope, J. C. (2005). Culture War? The Myth of a Polarized America (2nd ed.). New York: Pearson Longman.

Freeman, L.C. (1978). Centrality in social networks conceptual clarification. Social Networks, l(3), 215-239. doi: 10.1016/0378-8733(78)90021-7

Gelman, A., \& Azari, J. (2017). 19 things we learned from the 2016 election. Statistics and Public Policy, 4(1), 1-10.

Green, D. P., Palmquist, B., \& Schickler, E. (2002). Partisan Hearts and Minds: Political Parties and the Social Identities of Voters. New Haven: Yale University Press.

Greenberg, S. (2016). Trump/Clinton analysis. Retrieved from http://programs.clearerthinking.org/trump_clinton/trump_clinton_analysis.htm

Greenblatt, A. (2015). Millennial Generation: Will today's young adults change American society? CQ Researcher, 25(24), 553-576.

Hall, K., Goldstein, D. M., \& Ingram, M. B. (2016). The hands of Donald Trump: Entertainment, gesture, spectacle. Journal of Ethnographic Theory, 6(2), 71-100.

Hetherington, M. J. (2001). Resurgent Mass Partisanship: The role of elite polarization. American Political Science Review, 95(3), 619-631.

Hibbing, J. R., \& Theiss-Morse, E. (1995). Congress as public enemy: Public attitudes toward American political institutions: Cambridge University Press.

Hibbing, J. R., \& Theiss-Morse, E. (2002). Stealth democracy: Americans' beliefs about how government should work: Cambridge University Press. 
Hu, M., \& Liu, G. (2004). Mining and summarizing customer reviews. In W. Kim \& R. Kohavi (Eds.), Proceedings of the tenth ACM SIGKDD international conference on knowledge discovery and data mining (pp. 168-177). Washington, DC: ACM Press.

Inglehart, R., \& Norris, P. (July 29, 2016). Trump, Brexit, and the rise of populism: Economic have-nots and cultural backlash. HKS Working Paper No. RWP16-026. Retrieved from https://papers.ssrn.com/sol3/papers.cfm?abstract_id=2818659

Isenberg, D. J. (1986). Group polarization: A critical review and meta-analysis. Journal Of Personality and Social Psychology, 50(6), 1141-1151.

Iyengar, S., \& Westwood, S. J. (2015). Fear and loathing across party lines: New evidence on Group polarization. American Journal of Political Science, 59(3), 690-707.

Kaplan, M. F., \& Miller, C. E. (1987). Group decision making and normative versus informational influence: Effects of type of issue and assigned decision rule. Journal of Personality and Social Psychology, 53(2), 306-313.

Kendhammer, B. (2016). Muslims talking politics: framing Islam, democracy, and law in Northern Nigeria: University of Chicago Press.

Krueger, R. A., \& Casey, M. A. (2015). Focus groups: A practical guide for applied research (5th ed.).Thousand Oaks, CA: Sage.

Lasswell, H. D. (1950). Politics: Who gets what, when, how. New York: P. Smith.

Lasswell, H.D., \& Namenwirth, J.Z. (1969). The Lasswell value dictionary. New Haven: Yale University Press.

Lee, F. E. (2009). Beyond Ideology: Politics, Principles and Partisanship in the U.S. Senate. Chicago: University of Chicago Press.

Levendusky, M. (2009). The partisan sort: How liberals became Democrats and conservatives became Republicans: University of Chicago Press. 
Lohr, S., \& Singer, N. (2016, November 10). How data failed us in calling an election. New York Times. Retrieved from https://www.nytimes.com/2016/11/10/technology/the-data-said$\underline{\text { clinton-would-win-why-you-shouldnt-have-believed-it.html }}$

Lord, C. G., Ross, L., \& Lepper, M. R. (1979). Biased assimilation and attitude polarization: The effects of prior theories on subsequently considered evidence. Journal of Personality and Social Psychology, 37, 2098-2109.

MacWilliams, M. C. (2016). Who decides when the party doesn't? Authoritarian voters and the rise of Donald Trump. PS: Political Science \& Politics, 49(4), 716-721.

Masket, S. (2016). Did political science, or “political science,' get it wrong? Retrieved from https://www.vox.com/mischiefs-of-faction/2016/11/15/13639084/political-science$\underline{\text { forecasting }}$

McCarty, N., Poole, K. T., \& Rosenthal, H. (2016). Polarized America: The Dance of Ideology and Unequal Riches. Cambridge: MIT Press.

Mitchell, A., Gottfried, J., Kiley, J., \& Matsa, K. E. (2014). Political polarization \& media habits. Retrieved from http://www.journalism.org/2014/10/21/political-polarization-mediahabits/

Mohammad, S.M., \& Turney, P.D. (2010). Emotions evoked by common words and phrases: Using mechanical Turk to create an emotion lexicon. In Proceedings of the NAACL HLT 2010 workshop on computational approaches to analysis and generation of emotion in text (pp. 26-34). Stroudsburg: Association for Computational Linguistics

Mohammad, S.M., \& Turney, P.D. (2013). Crowdsourcing a word-emotion association lexicon. Computational Intelligence, 29, 436-465.

Morris, S. B., \& DeShon, R. P. (2002). Combining effect size estimates in meta-analysis with repeated measures and independent-groups designs. Psychological Methods, 7, 105-125. 
Moscovici, S., \& Zavalloni, M. (1969). The group as a polarizer of attitudes. Journal of Personality and Social Psychology, 12 (2): 125-135.

Nomani, A. Q. (2016). I'm a Muslim, a Woman and an Immigrant. I Voted for Trump. Washington Post, 10.

Pennebaker, J.W., Boyd, R.L., Jordan, K., \& Blackburn, K. (2015). The development and psychometric properties of LIWC2015. Austin, TX: University of Texas at Austin. doi: 10.15781/T29G6Z

Perneger, T.V. (1998). What's wrong with Bonferroni adjustments. The BMJ, 316(7139), 12361238.

Pew Research Center (2016). On Immigration Policy, Partisan Differences but Also Some Common Ground. Retrieved from http://www.people-press.org/2016/08/25/onimmigration-policy-partisan-differences-but-also-some-common-ground/

Pew Research Center (2017). Public opinion on abortion. Retrieved from: http://www.pewforum.org/fact-sheet/public-opinion-on-abortion/

Poole, K. T., \& Rosenthal, H. L. (2007). Ideology and Congress. New Brunswick, NJ: Transaction Publishers.

Price, V., Goldthwaite, D., Cappella, J. N., \& Romantan, A. (2003). Online discussion, civic engagement, and social trust. Paper presented at the 2nd Annual Pre-APSA Conference on Political Communication.

Prior, M. (2007). Post-broadcast democracy: How media choice increases inequality in political involvement and polarizes elections: Cambridge University Press.

Robins, G., Lewis, J.M., \& Wang, P. (2012). Statistical network analysis for analyzing policy networks. The Policy Studies Journal, 40(3), 375-401. 
Scherer, K.R. (2005). What are emotions? And how can they be measured? Social Science Information, 44, 695-729.

Siew, C.S.Q., McCartney, M.J., \& Vitevitch, M.S. (2019). Using network science to understand statistics anxiety among college students. Scholarship of Teaching and Learning in Psychology, Advance online publication.

Sinclair, B. (2014). Party Wars: Polarization and the Politics of National Policy Making (Vol. 10): University of Oklahoma Press.

Stenner, K., \& Haidt, J. (2018). Authoritarianism is not a Momentary Madness, but an Eternal Dynamic within Liberal Democracies. In C. R. Sustein (Ed.), Can It Happen Here?: Authoritarianism in America (pp. 175-220). New York: Harper Collins.

Stewart, D. W., Shamdasani, P. N., \& Rook, D. W. (2007). Focus groups: Theory and practice (Vol. 20). Thousand Oaks, CA: Sage.

Stone, P., Dunphy, D.C., Smith, M.S., Ogilvie, D.M., \& Associates. (1966). The general inquirer: A computer approach to content analysis. Cambridge: MIT Press

Suhay, E. (2015). Explaining group influence: The role of identity and emotion in political conformity and polarization. Political Behavior, 37(1), 221-251.

Sunstein, C. R. (2002). The law of group polarization. Journal of Political Philosophy, 10(2), 175.

Sunstein, C. R. (2018). \# Republic: Divided democracy in the age of social media: Princeton University Press.

Tajfel, H. (1978). Social categorization, social identity, and social comparison. In H. Tajfel (Ed.), Differentiation between groups: Studies in the social psychology of intergroup relations. London: Academic Press.

Theriault, S. M. (2008). Party Polarization in Congress. Cambridge: Cambridge 
University Press.

Turner, J. C. (1985). Social categorization and the self-concept: A social cognitive theory of group behavior. In E. Lawler (Ed.), Advances in group processes: Theory and research. Greenwich, CT: JAI Press.

Turner, J. C. (1991). Social influence. Bristol, PA: Open University Press.

Van Swol, L. M. (2009). Extreme members and group polarization. Social Influence, 4(3), 185199.

Walsh, K. C. (2012). Putting inequality in its place: Rural consciousness and the power of perspective. American Political Science Review, 106(3), 517-532.

Wojcieszak, M., \& Price, V. (2010). Bridging the divide or intensifying the conflict? How disagreement affects strong predilections about sexual minorities. Political Psychology, 31(3), 315-339.

Zaller, J. (1992). The nature and origins of mass opinion. Cambridge, England; New York, NY: Cambridge University Press. 
Table 1.

Responses on demographics questionnaire in percentages for Trump non-supporters.

\begin{tabular}{|c|c|c|}
\hline Variable & $\underline{\text { Response Categories }}$ & Percent \\
\hline \multirow[t]{7}{*}{ Political Ideology } & Very liberal & 21.6 \\
\hline & Somewhat liberal & 24.3 \\
\hline & Slightly liberal & 13.5 \\
\hline & Neither liberal nor conservative & 27.0 \\
\hline & Slightly conservative & 5.4 \\
\hline & Somewhat conservative & 5.4 \\
\hline & Very conservative & 2.7 \\
\hline \multirow[t]{7}{*}{ Political Party Identification } & Strong Democrat & 43.2 \\
\hline & Weak Democrat & 21.6 \\
\hline & Independent that leans Democrat & 13.5 \\
\hline & Pure Independent & 2.7 \\
\hline & Independent that leans Republican & 8.1 \\
\hline & Weak Republican & 8.1 \\
\hline & Strong Republican & 0 \\
\hline \multirow[t]{5}{*}{ Religious Service Attendance } & More than once a week & 5.4 \\
\hline & Once a week & 35.1 \\
\hline & 1-2 times a month & 32.4 \\
\hline & 1-2 times a year & 10.8 \\
\hline & None in past year & 16.2 \\
\hline \multirow[t]{5}{*}{ Religious Affiliation } & Christianity & 70.3 \\
\hline & Judaism & 2.7 \\
\hline & Buddhism & 2.7 \\
\hline & Other & 8.1 \\
\hline & Not religious & 16.2 \\
\hline \multirow[t]{3}{*}{ Education } & High School & 27 \\
\hline & Vocational/Technical School & 2.7 \\
\hline & Some college & 70.3 \\
\hline
\end{tabular}




\begin{tabular}{lll}
\hline Household income & \multicolumn{1}{l}{ Under 10,000} & 13.5 \\
\cline { 2 - 3 } $10,000-19,999$ & 16.2 \\
\cline { 2 - 2 } $20,000-29,999$ & 5.4 \\
\cline { 2 - 2 } $30,000-39,999$ & 2.7 \\
\cline { 2 - 2 } $40,000-49,999$ & 16.2 \\
\cline { 2 - 2 } $50,000-74,999$ & 2.7 \\
\hline $75,000-99,000$ & 5.4 \\
\cline { 2 - 2 } $99,000-100,000$ & 13.5 \\
\cline { 2 - 2 } Over 150,000 & 18.9 \\
\hline I do not know & 13.4 \\
\hline
\end{tabular}




\section{Table 2.}

Responses to levels of support $(M, S D)$ for Trump's view on the following items among Trump's opponents. The response scale used was $1=$ Extremely opposed to $9=$ Extremely in favor of. Bigger numbers indicate greater level of support.

Change column indicates the effect size (Cohen $d$ ) associated with the change. Negative $d$ s signify that participants were more in favor of post discussion.

\begin{tabular}{lccccc}
\hline & \multicolumn{2}{c}{ Pre-discussion } & Post-discussion & Change \\
\hline & $M$ & $S D$ & $M$ & $S D$ & $d$ \\
\hline The Trade War & 2.69 & 1.79 & 2.86 & 1.94 & -0.09 \\
Illegal Immigration & $2.65^{*}$ & 2.03 & $2.03^{*}$ & 1.79 & 0.36 \\
The 2nd Amendment & 3.16 & 2.5 & 3.19 & 2.41 & -0.02 \\
Political Correctness & $2.6^{*}$ & 2.2 & $1.97^{*}$ & 1.88 & 0.34 \\
Education & 4.81 & 2.76 & 4.3 & 2.54 & 0.23 \\
The Military & $3.3^{*}$ & 2.33 & $2.65^{*}$ & 2.12 & 0.35 \\
The Economy & 3.53 & 2.5 & 3.25 & 2.88 & 0.10 \\
Abortion & 1.89 & 1.82 & 1.84 & 1.8 & 0.03 \\
Torture & 2.32 & 2 & 1.92 & 1.53 & 0.20 \\
Women & $1.95^{*}$ & 1.91 & $1.41^{*}$ & 1.46 & 0.46 \\
Veterans & $4.03^{* *}$ & 2.8 & $3.1 * *$ & 2.88 & 0.55 \\
Veterans-POW & 2.54 & 2.04 & 2.19 & 2.08 & 0.19 \\
Disabled Individuals & 1.76 & 1.75 & 1.54 & 1.63 & 0.14 \\
Protestors at his political & 1.95 & 1.86 & 1.62 & 1.44 & 0.18 \\
rallies & & & & & \\
\hline
\end{tabular}

Note. $* * p<.005, * p \leq .05$ 
Table 3.

Top 5 processes for each polarized issue.

\begin{tabular}{|c|c|c|c|c|c|}
\hline Influence Rank & Immigration & Military & Political_Correctness & Women & Veterans \\
\hline 1 & Submit & Know & Negative emotions & Politics & Military \\
\hline 2 & Power total & If & Hostile & Negative emotions & Power authoritative Ps \\
\hline 3 & Doctrine & Need & Social relations & Power total & Wealth \\
\hline 4 & Religion & Negative outlook & Power authoritative Ps & Know & Power total \\
\hline 5 & Military & Dominance & Wealth & Vice & Power ordinary Ps \\
\hline
\end{tabular}

Note. See Supplemental Online Appendix at

https://www.dropbox.com/s/oqrltq0kv2o2qx0/Supplemental\%20Online\%20Appendix.docx?dl=0

for detailed description of and examples for each indicator.

Submit: submission to authority or power, dependence on others, vulnerability to others, or withdrawal.

Power total: the whole domain of power.

Doctrine: organized systems of belief or knowledge, including those of applied knowledge, mystical beliefs, and arts that academics study.

Know: awareness or unawareness, certainty or uncertainty, similarity or difference, generality or specificity, importance or unimportance, presence or absence, as well as components of mental classes, concepts or ideas.

If: feelings of uncertainty, doubt and vagueness.

Need: the expression of need.

Negative: negative outlook.

Hostile: an attitude or concern with hostility or aggressiveness.

Power authoritative Ps: power authoritative participants, individual and collective actors in power process.

Vice: an assessment of moral disapproval or misfortune.

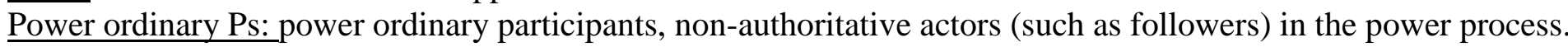


Table 4.

QAP correlations among issues producing group polarization effects.

\begin{tabular}{|c|c|c|c|c|c|}
\hline & Immigration & Military & $\begin{array}{c}\text { Political } \\
\text { Correctness }\end{array}$ & Veterans & Women \\
\hline Immigration & -- & & & & \\
\hline Military & $n s$ & -- & & & \\
\hline Political Correctness & $.067 *$ & $.236 * * *$ & -- & & \\
\hline Veterans & $n s$ & $.276 * * *$ & $.130 * * *$ & -- & \\
\hline Women & $.075^{*}$ & $.230 * * *$ & $.306 * * *$ & $.111^{* *}$ & -- \\
\hline
\end{tabular}

Note. $* p<.05, * * p<.01, * * * p<.001$ 